\title{
Polar Cycles
}

\section{Charles Whitmore ${ }^{1}$}

Received: 25 October 2017 / Accepted: 28 November 2017 / Published online: 18 December 2017

(C) Academic Psychiatry 2017

I'm held down by leather lashes and pumped full of dopy blockers forced to sleep by treatment planning stopping screaming thoughts and stalkers

waking later, mouth of cotton my mind is foggy, lacking purpose a cycle broken, shuttered down my sense of self now breaks the surface

I'm sitting up and safety planning time to go, I shaved and showered given meds I'll someday stop to let that cycle show its power ramping up, I'm simply helpless left with no one, broke and homeless my life a living poor prognosis

buried young and deep and hopeless

Charles Whitmore charles.whitmore@ucdenver.edu

1 University of Colorado School of Medicine, Aurora, CO, USA 